\title{
Thrombotic Microangiopathies, Thrombotic Thrombocytopenic Purpura, and ADAMTS-13
}

\author{
Kent Chapman, B.Sc. (Biomed.) ${ }^{1}$ Michael Seldon, F.R.A.C.P., F.R.C.P.A., M.B.B.S., B.Sc. (Med.) ${ }^{2}$ \\ Ross Richards, Ph.D., M.App.Sc. ${ }^{3}$
}

${ }^{1}$ Department of Haematology, Hunter Area Pathology Service, John Hunter Hospital, Newcastle, NSW, Australia

2 Calvary Mater Hospital, Newcastle, NSW, Australia

${ }^{3}$ Charles Sturt University, Wagga Wagga, NSW, Australia

\begin{abstract}
Address for correspondence and reprint requests Kent Chapman, B.Sc. (Biomed.), Department of Haematology, Hunter Area Pathology Service, John Hunter Hospital, Lookout Road, New Lambton 2300, NSW, Australia (e-mail: kent.chapman@hnehealth.nsw.gov.au).
\end{abstract}

Semin Thromb Hemost 2012;38:47-54.

\begin{abstract}
Keywords

- ADAMTS-13

- thrombotic thrombocytopenic purpura

- thrombotic microangiopathy

- CD36

- von Willebrand factor

Thrombotic microangiopathy (TMA) is a term used to describe a group of disorders characterized by hemolytic anemia (with prominent red blood cell fragmentation), thrombocytopenia, and thrombosis in the microvasculature. It may be used when describing patients with thrombotic thrombocytopenic purpura (TTP), hemolytic uremic syndrome, atypical hemolytic uremic syndrome, as well as a myriad of other disorders in which the TMA may be secondary to another disease or disorder. While limited information exists as to the exact cause of microthrombosis in many TMA, recent advances have been made in the understanding of TTP and its pathophysiology. This progress can be attributed to discovery of the von Willebrand factor cleaving protease ADAMTS-13 (a disintegrin and metalloproteinase with a thrombospondin type 1 motif, member 13), whose absence in TTP has given the disorder a distinct molecular identity. The discovery of this metalloprotease has prompted a significant amount of research relating to its role in TTP as well as its general function in hemostasis. The exact mechanisms by which this metalloprotease achieves its role are slowly being understood and these now provide other avenues by which TMA may occur.
\end{abstract}

Thrombotic microangiopathy (TMA) is a clinicopathological syndrome that refers to a combination of microangiopathic hemolytic anemia, thrombocytopenia, and microvascular thrombosis, regardless of cause or specific tissue involvement. ${ }^{1}$ The pathological process begins with an abnormal biochemical trigger, or pathological insult, that leads to thrombus formation in the microvasculature of various organs. $^{2}$ The thrombosis in the microcirculation leads to a consumptive thrombocytopenia and creates an abnormally high level of shear stress in the small vessels. ${ }^{2,3}$ The shear stress eventually leads to the mechanical destruction of erythrocytes and the presence of fragmented erythrocytes (schistocytes) in the peripheral blood.

TMA may precipitate in a variety of disorders including thrombotic thrombocytopenic purpura (TTP), hemolytic uremic syndrome (HUS), atypical hemolytic uremic syndrome
(aHUS), systemic vasculitis, malignant hypertension, catastrophic antiphospholipid antibody syndrome, scleroderma in renal crisis, disseminated malignancy, postpartum acute renal failure, hemolysis with elevated liver enzymes and low platelets (HELLP) syndrome, transplant related TMA, cancer and chemotherapy related TMA, or even, disseminated intravascular coagulation (DIC). ${ }^{4,5}$ For many years the distinction between these disorders has remained purely clinical and this has led some to believe that these disorders were different manifestations of the same pathological process. ${ }^{4,6}$ However, there has been much scientific progress in the understanding of the pathogenesis of TTP over the past 20 years, particularly since the discovery and identification of ADAMTS-13 (A Disintegrin And Metalloproteinase with ThromboSpondin-1-like motifs, member $\mathbf{1 3}$ of this family of metalloprotease) by two independent groups in $19966^{7,8}$ A deficiency of this von
Issue Theme Hot Topics III; Guest Editor, Emmanuel J. Favaloro, Ph.D., M.A.I.M.S., F.F.Sc. (RCPA)
Copyright @ 2012 by Thieme Medical Publishers, Inc., 333 Seventh Avenue, New York, NY 10001, USA. Tel: +1(212) 584-4662.
DOI http://dx.doi.org/ 10.1055/s-0031-1300951. ISSN 0094-6176. 
Willebrand factor (VWF) cleaving protease has been identified as the causative agent in many cases of clinical TTP, allowing its distinction from other causes of TMA (particularly HUS and aHUS). Since its discovery, ADAMTS-13 has been the focus of a significant amount of research not only for its role in the pathogenesis of TTP, but also for its general function in hemostasis. Insights into exactly how ADAMTS-13 acts have unveiled other potential mechanisms which may help explain other causes of TMA. This article reviews the history of TTP, the role of VWF and ADAMTS-13 in its pathogenesis, as well as the role that ADAMTS-13 may play in other TMA, in part providing updates to previous articles published in Seminars in Thrombosis $\mathcal{E}$ Hemostasis. ${ }^{9,10}$ The article will not review HUS and aHUS, or describe assays for ADAMTS-13, as these topics have recently been reviewed in this journal. ${ }^{11-13}$

\section{The Evolution of TTP}

As a disease, TTP (also known as Upshaw-Schülman syndrome) has been slow to yield its secrets. TTP was first identified as a distinct disease entity in 1924 by Dr. Eli Moschcowitz, who described a 16-year-old girl admitted for acute fever, severe anemia, heart failure, and stroke, followed by paralysis, coma, and death within 2 weeks. In the postmortem examination, Moschcowitz highlighted the presence of diffuse hyaline thrombi in the arterioles of the organs as the key pathological finding. ${ }^{14}$ He postulated that a "powerful poison or toxin resulted in agglutination and hemolysis of red blood cells," which then resulted in terminal arteriole and capillary hyaline thrombosis. Despite being the first to describe the disease, Moschcowitz made no mention in his original findings of a decrease in platelets as a clinical or pathological feature of the disease.

Over 10 years later Baehr et al observed that the hyaline thrombi (previously described by Moschcowitz) was rich in platelet aggregates indicating some form of platelet involvement. ${ }^{15} \mathrm{~A}$ further 10 years passed before the role of platelets was reemphasized by Singer et al proposing the use of the term, "thrombotic thrombocytopenic purpura," to describe the disease. ${ }^{16}$ Later, in 1966, after reviewing some 250 patients reported with TTP including 16 new cases, Amorosi and Ultmann, established a pentad of clinical and laboratory features which are still considered to be the key diagnostic criteria in TTP: Microangiopathic hemolytic anemia with schistocytes, thrombocytopenia, neurological symptoms (often fluctuating), renal dysfunction, and fever. ${ }^{17}$ Despite this being a landmark in the clinical diagnosis of TTP, the pathophysiological understanding of the disease remained a mystery at this time, and for some time to come.

The first clue as to the cause of TTP was uncovered by Moake et al when they observed an association between patients with chronically relapsing TTP and unusually large molecular weight VWF multimers (ultralarge von Willebrand factor; ULVWF). ${ }^{18}$ As these ULVWF disappeared in the remission phases of TTP, Moake et al hypothesized that their disappearance may be responsible for the in vivo platelet clumping observed in the microcirculation. In a subsequent series of studies, ULVWF multimers were found to be hyperactive in binding and aggregating platelets. ${ }^{19,20}$ This insight added substantial weight to the idea that these ULVWF multimers were central to the disease process of TTP. Moake et al speculated further, by suggesting that impaired degradation by a then unknown "depolymerase" may give rise to these ULVWF multimers. This unknown depolymerase was subsequently identified independently by two groups in $1996^{7,8}$ and called the VWF cleaving protease. Five years later, the enzyme was determined to be ADAMTS-13, the thirteenth member of the ADAMTS metalloprotease family ${ }^{21}$ and its gene and cDNA were subsequently characterized. ${ }^{22,23}$

A direct link between ADAMTS-13 deficiency and TTP pathogenesis has now been firmly established for over 10 years and a large amount of data in this area has been produced over this period. Mutations in the ADAMTS-13 gene have been described in patients with familial TTP, ${ }^{24,25}$ whereas the cause of acute acquired TTP has been shown to be autoimmune in its pathogenesis. ${ }^{26,27}$ Diagnostic assays for ADAMTS-13 activity and autoantibody detection have aided in the recognition of this rare disease and provided a means to enable a definitive diagnosis by clinicians. ${ }^{13}$

\section{Pathophysiology of TTP}

\section{The Role of VWF}

To better understand the pathophysiology of TTP it is appropriate to first review the normal function, structure, and biosynthesis of VWF. VWF is a multifunctional multimeric glycoprotein (GP) that performs vital roles in both thrombosis and hemostasis. One of the most important functions of VWF is to act as an intermediary between subendothelial structures (primarily collagen) and platelet glycoprotein Ib $\alpha$ (GPIb $\alpha){ }^{28}$ This action represents the first line of defense against bleeding from an injured vessel and is termed "primary hemostasis." Once bound to the subendothelium, VWF then facilitates platelet recruitment via platelet-platelet interactions by recruitment of a second platelet receptor, glycoprotein IIb/IIIa (GPIIb/IIIa) ${ }^{28}$ VWF also fulfills another role in hemostasis by acting as a carrier protein for coagulation factor VIII, protecting it from rapid proteolytic degradation and thereby prolonging its half-life in the circulation. $^{29}$

The synthesis of VWF is restricted to endothelial cells and megakaryocytes, which is physiologically appropriate given the role of these cells. VWF is produced as pre-pro-VWF that comprises a signal peptide, a propeptide, and the mature VWF subunit (-Fig. 1). After removal of the signal peptide (SP), pro-VWF subunits associate in the endoplasmic reticulum in "tail-to-tail" dimers by the formation of disulfide bonds between CK domains, after which dimers further multimerize by forming "head-to-head" disulfide bonds between the D3 domains in the Golgi. ${ }^{30}$ As well as being released by endothelial cells in the blood and subendothelial matrix constitutively, ${ }^{29}$ large amounts of VWF (particularly rich in ULVWF multimers) are also stored within Weibel-Palade bodies of endothelial cells and the $\alpha$-granules of platelets. ${ }^{31}$ 


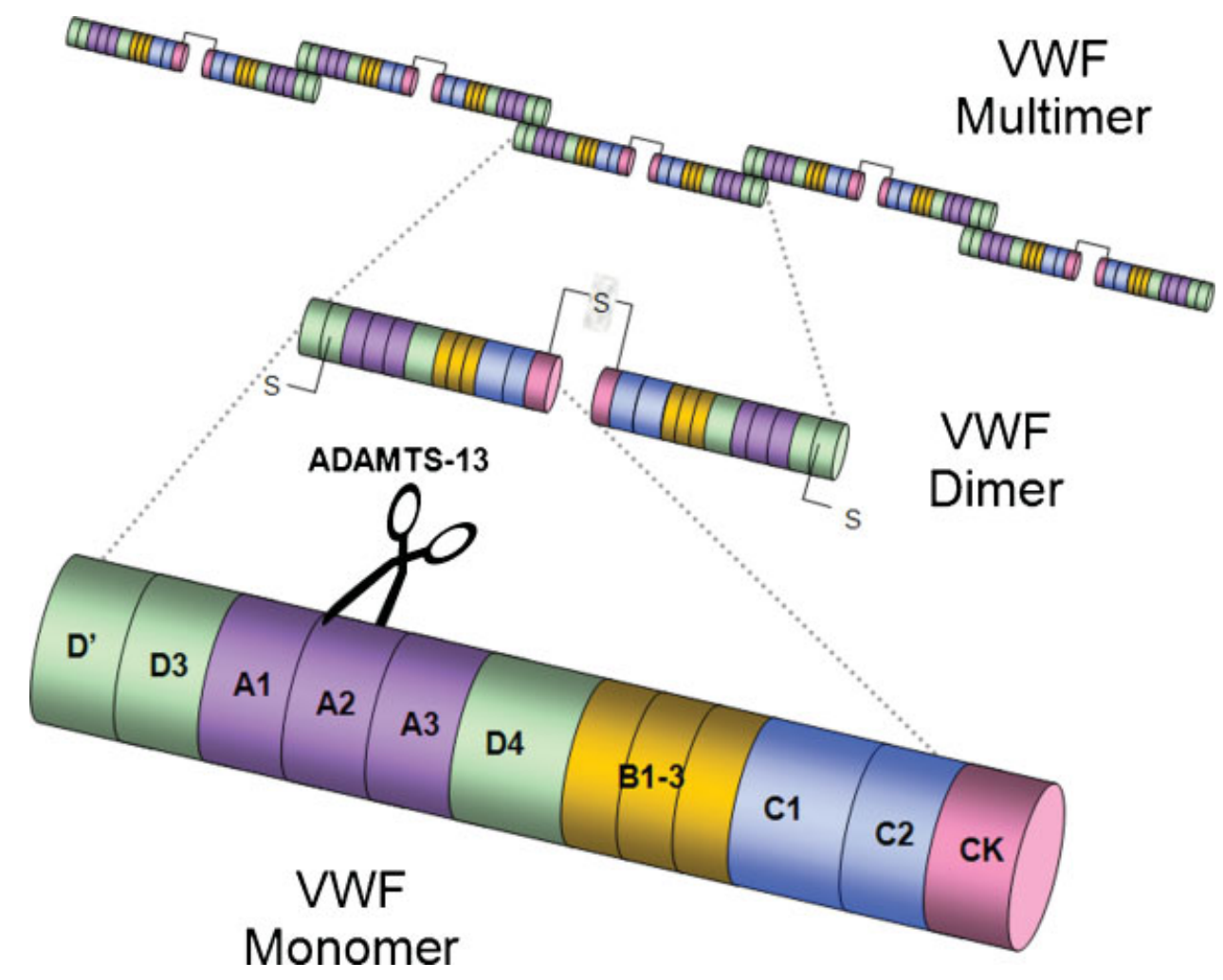

Figure 1 Domain structure of von Willebrand factor (VWF) showing ADAMTS-13 (a disintegrin and metalloproteinase with a thrombospondin type 1 motif, member 13) cleavage site within the A2 domain. Schematic representation of monomeric, dimeric, and multimeric VWF.

These stores may be released at sites of vascular injury to deliver the most thrombogenic forms of VWF directly where needed.

The multiple and varying functions of VWF are made possible by its complex multidomain primary structure, its ability to form dimers with itself, and the ability of these dimers to then form multimers ( $\boldsymbol{- F i g . 1}$ ). This allows VWF to exist in the plasma as a series of oligomers containing a variable number of subunits ranging from a minimum of 2 to a maximum of 40 , with the smallest dimer being only 540 $\mathrm{kDa}$ and the largest multimers having molecular weights in excess of $20,000 \mathrm{kDa}^{30}$ The multimeric composition of plasma VWF is critical in determining the functional ability of VWF to achieve its platelet adhesive role. ${ }^{31}$ The high molecular weight VWF (HMWVWF) multimers display significantly greater ability to bind both collagen and platelets and are thus more efficient in inducing platelet aggregation. $^{32,33}$ The importance of these larger multimers is highlighted by the bleeding tendency observed in patients with mutations in VWF, in whom multimerization does not occur normally. ${ }^{28}$

In normal hemostatic conditions, these HMWVWF multimers have a highly folded quaternary structure that protects the vasculature from their highly thrombogenic platelet adhesive function. However, under conditions of shear stress such as those observed in vessel damage, these HMWVWF multimers unfold, thereby exposing their functional sites and allowing interaction with platelets and collagen.

\section{The Role of ADAMTS-13}

The physiological control of VWF multimer length is primarily accomplished by the enzyme, ADAMTS-13. This is achieved through its ability to cleave multimeric VWF into smaller units, thereby decreasing their ability to induce platelet adhesion and aggregation (-Fig. 2). This process of proteolytic cleavage is in a delicate balance between reducing the size of VWF multimers so that they remain sufficiently functional to stop bleeding, but also cleaving them appropriately to avoid unwanted thrombosis. A severe deficiency of ADAMTS-13 causes accumulation of highly thrombogenic forms of VWF (i.e., the ULVWF multimers) in plasma. ${ }^{7,8}$ The relatively higher shear forces in the microcirculation cause these ULVWF multimers to unfold, thereby activating their functional ability to aggregate platelets and causing the formation of platelet-rich microthrombi (-Fig. 2 ).

It is now generally accepted that a severe deficiency (defined as less than $10 \%$ of normal) in the activity of ADAMTS-13, either congenital or acquired, is the cause of TTP. $^{34}$ of those patients diagnosed with TTP, the overwhelming majority have been demonstrated to be acquired deficiencies of ADAMTS-13, caused by inhibitory autoantibodies in the plasma of those afflicted. ${ }^{26}$ The familial form of TTP is far less prevalent than its acquired counterpart, perhaps due to its likely incompatibility with life. Those patients who do survive with the congenital form of TTP tend to display variable symptoms. Some may display a chronic unrelenting thrombotic tendency, while others have only episodic bouts of thrombotic microangiopathy 

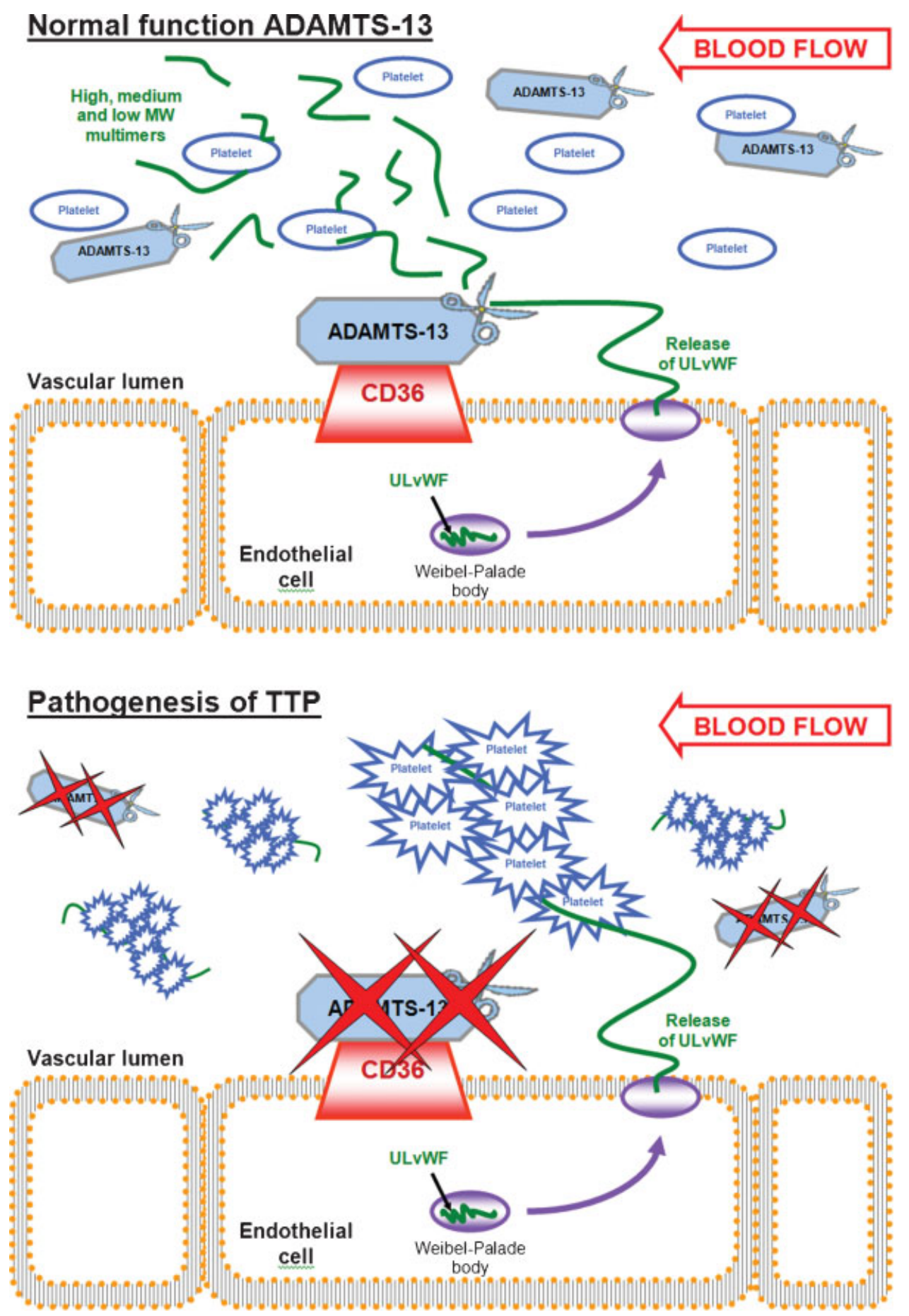

Figure 2 Schematic diagram of normal versus severely reduced ADAMTS-13 (a disintegrin and metalloproteinase with a thrombospondin type 1 motif, member 13) activity. When ADAMTS-13 is functioning normally, ultralarge von Willebrand factor (ULVWF) is cleaved at the endothelial cell surface thereby decreasing its platelet adhesive function. In thrombocytopenic purpura (TTP), the ULVWF multimers released are not cleaved due to a reduction in ADAMTS-13 activity. The resultant ULVWF multimers unfold in the microcirculation (due to increased shear force at these locations) thereby exposing their active sites and inducing pathological platelet aggregation.

despite having undetectable or extremely low levels of ADAMTS-13 at all times. ${ }^{35}$ The first episode of TTP is often during infancy or early childhood, but adult onset cases have also been reported..$^{35,36}$ The mechanism for the delayed onset remains unclear, but the acute episodes are often preceded with infection, pregnancy, and surgery, which are all recognized to result in ULVWF multimer secretion from endothelial cells, suggesting that a triggering event might be required. ${ }^{37}$

Since its discovery, much has been learned about the synthesis, structure, and function of ADAMTS-13. The recognition of its absence as the causal agent in the pathogenesis of 
TTP (both congenital and acquired) has not only provided a definitive cause for this disease, but has also provided further clues to the potential causes of other TMAs. The control of ADAMTS-13 function is only now beginning to be understood, but it seems likely that other augmentations in the in vivo activity of ADAMTS-13, such as its ability to bind its substrate or localize itself to the endothelial cell surface, could also be a potential cause of TMA.

\section{Control of ADAMTS-13 Function: Clues to Other TMA}

As a constitutively active enzyme, the proteolytic activity of ADAMTS-13 is primarily controlled by its limited access to the $\mathrm{Tyr}^{1605}$-Met ${ }^{1606}$ cleavage site buried within the collapsed structure of the $\mathrm{A} 2$ domain of $\mathrm{VWF}^{38}$ As discussed earlier, VWF undergoes conformational changes under conditions of shear force. These conformational changes not only expose sites required for platelet and endothelial interactions, but they also control the access of ADAMTS-13 to its VWF cleavage site. This property ensures that there is no indiscriminate or unwanted cleavage of VWF which could lead to uncontrolled bleeding.

Another important control mechanism for ADAMTS-13 appears to be its endothelial localization. Despite circulating in the plasma as a free enzyme, ADAMTS-13 has been shown to bind endothelial cells to facilitate the cleavage of ULVWF multimers released from Weibel-Palade bodies. ${ }^{39}$ The binding of ADAMTS-13 to the endothelial surface allows control of multimer length at their sites of release from intracellular stores. This binding is speculated to occur with CD36 (glycoprotein IV or $\mathrm{Nak}^{\mathrm{a}}$ antigen) via one of the protease's many thrombospondin domains. The significance of ADAMTS-13 binding to endothelial CD36 remains to be clarified, but there are several clues that point toward its relevance.

The importance of this cellular localization by ADAMTS-13 is highlighted by work from Reiter et al who showed a halving of plasma ADAMTS-13 activity postadministration of DDAVP (desmopressin). ${ }^{40}$ This drug causes release of VWF from endothelial cells and is used in the treatment of von Willebrand disease (VWD, which defines a disorder characterized by a loss of VWF or VWF function). These workers postulated that the drop in plasma ADAMTS-13 may represent the enzyme being exhausted by excessive amounts of substrate (i.e., VWF) being released as a result of DDAVP administration. Although this explanation did support the findings, the alternative hypothesis, that the decrease in plasma ADAMTS-13 activity observed may actually represent an increase in the level of activity of this enzyme in vivo would also hold true. Thus, the decrease in "apparent" plasma activity could be caused by an increase in the level of ADAMTS-13 binding to the endothelial cell surface, where it is primarily required to function. Therefore, it is postulated that the transition of ADAMTS-13 from a liquid to a solid phase, or the movement of the enzyme from the plasma to the endothelial cell surface, may allow it to more efficiently cleave ULVWF multimers being released from endothelial cells, and thus account for the decrease in plasma ADAMTS-13 observed by Reiter et al.

Considering that VWF is an acute phase protein that becomes raised as part of a normal acute phase response, ${ }^{41}$ the increase in plasma VWF observed during the acute phase of disease is a result of increased release of VWF from WeibelPalade bodies within the endothelial cells, much like that seen in DDAVP treatment. It seems likely then, that ADAMTS-13 would migrate from the plasma to the endothelial cell surface (binding CD36) as part of this response to facilitate cleavage of the ULVWF multimers being released. This migration could potentially cause a concomitant decrease in plasma ADAMTS13 "quantity." Studies into ADAMTS-13 levels in health and disease support this idea. In a study by Mannucci et al, decreased levels of plasma ADAMTS-13 activity were found in patients postsurgery, patients with chronic renal insufficiency, patients with acute inflammatory illness, and those who were pregnant (second and third trimesters). ${ }^{42}$ All of these clinical conditions can be associated with high levels of VWF and hence low plasma levels of ADAMTS-13 due to increased endothelial cell binding of the protease.

The presence of endothelial cell-bound ADAMTS-13 may also help explain studies into the half-life of this protease in patients with congenital forms of the TTP. In spite of ADAMTS13 having a plasma half-life of 2 to 4 days, ${ }^{43}$ these patients survive using infusions of fresh frozen plasma every 3 weeks. $^{44}$ A reserve store of endothelial cell-bound ADAMTS-13 could potentially allow a prolonged survival of the enzyme in vivo and thereby provide prolonged protection from unwanted thrombosis while reflecting a setting of severe plasma deficiency. Similarly, patients with acquired TTP may show clinical progress with plasma infusions despite an absence of measurable protease activity. In these patients, it is proposed that the membrane-bound protease activity may be restored before plasma levels are normalized.

Furthering the notion of a potential role of CD36, there was already an association described between the presence of anti-CD36 antibodies and patients with clinical TMA before the discovery of ADAMTS-13. In 1994, Tandon et $\mathrm{al}^{45}$ highlighted the potential role of anti-CD36 antibodies by demonstrating their presence in over $70 \%$ of patients with clinical TTP. The high number of antibody positive patients in this study may further suggest the importance of CD36 in anchoring ADAMTS-13 to the endothelial cell surface. Further support was provided by Schultz et al, who found a similar prevalence in another population of clinical TMA patients. ${ }^{46}$ The presence of these CD36 antibodies could potentially inhibit the binding of ADAMTS-13 to the endothelial cell surface thereby removing the protease from the proximity of any ULVWF that is released. This may ultimately result in a disease which is clinically identical to TTP, while still maintaining normal plasma levels of the protease. This scenario may also be dependent on secondary trigger(s) capable of inducing VWF release (such as concomitant illness), which may further exacerbate the effect of ADAMTS-13 in not finding its endothelial target (i.e., CD36). A study by Rock et al also suggest CD36 involvement, with the identification of antibodies to this glycoprotein being implicated in patients 
with systemic lupus erythematosus who had thrombotic complications. $^{47}$

The relevance of CD36 antibodies has also recently been highlighted by Rock and Clark who reported their presence in patients with diarrhea-positive HUS. ${ }^{48}$ In this study, 9 out of the 11 patients with HUS were found to have antibodies to CD36 capable of inducing platelet aggregation in washed platelets from normal donors. This finding has firmly implicated these antibodies in the mechanism of microthrombosis in this disease. In the same study, these antibodies were shown to cross-react with verotoxin-2 (produced by the causative microbial agent in HUS), suggesting an immunological pathogenesis for HUS. Unfortunately, no direct study has been performed to determine whether these specific antibodies may also inhibit the in vivo activity of ADAMTS13. In 2005, however, a study by Nolasco et $\mathrm{al}^{49}$ showed that verotoxin directly inhibited the ability of ADAMTS-13 to cleave ULVWF-platelet strings released from cultured endothelial cells. The exact mechanism by which verotoxin may inhibit ADAMTS-13, remains unclear. Regardless of the role of ADAMTS-13 in HUS, these findings have also introduced the possibility of "autoimmune HUS," in which the preceding diarrheal symptoms would be absent. If this proves to be true, it seems possible that some diarrhea negative HUS patients may actually have autoimmune anti-CD36 antibodies.

In the world of platelet serology, CD36 is known as the $\mathrm{Nak}^{\mathrm{a}}$ antigen (or glycoprotein IV). Antibodies to $\mathrm{Nak}^{\mathrm{a}}$ have been found in a few rare patients who lack this antigen. A report by Morishita et al describes one such patient who was discovered after a transfusion of their donated plasma was found to cause a life-threatening adverse reaction followed by thrombocytopenia in a recipient. ${ }^{50}$ The same patient's plasma was further studied by Wakamoto et al to assess its response to different recipients. ${ }^{51}$ This study showed that there was profound heterogeneity in platelet responsiveness among normal donors when challenged with the same anti-CD36 antibody. This variation in responsiveness was found to be due to differences in the expression of CD36 and the FcrRIIa receptor on the normal platelets. The dependence on the presence of these receptors suggests that interactions between the Fc portion of the antibody and the FcrRIIa receptor are required to facilitate platelet activation, much like many other monoclonal antibodies that are capable of activating platelets. ${ }^{52}$ These data may indicate then, that not all people are as susceptible to the potentially detrimental effects of these antibodies.

Although only limited data exist on the relationship between anti-CD36 antibodies and clinical TMA, the correlation seems very strong. Whether the resulting clinical manifestations are purely a consequence of the ability of these antibodies to cause platelet activation or whether an inhibition of ADAMTS-13 activity is involved remains to be seen. It seems likely that the specificity of these antibodies will dictate their pathological importance. As stated previously, the correlation between the presence of these anti-CD36 antibodies and clinical TMA is not a new discovery. The potential importance of antibodies interfering with ADAMTS-13 on the other hand is an idea that has only been given limited attention. Further research is required in this area to determine its true significance.

The concept of ADAMTS-13 binding to CD36 may also suggest that platelet-derived microparticles (containing CD36) could additionally interact with the protease. An increased microparticle count could potentially compete in binding ADAMTS-13, thereby reducing its interaction with the endothelium and consequently reducing multimer cleavage. This may then contribute to the increased rates of thrombosis observed in these patients, although no studies to date have been performed.

Finally, there appears to be a physiological mechanism that may contribute to the control of ADAMTS-13. Despite George describing the protease to be resistant to all protease inhibitors, $^{53}$ evidence suggests there may be inhibition of ADAMTS- 13 by plasmin and thrombin. ${ }^{54}$ It is proposed that these coagulation proteins may modulate the activity of ADAMTS-13 at the sites of hemostatic plug formation. This idea was recently supported by Feys et al who described a patient with severe ADAMTS-13 deficiency that was not congenital, and displayed no detectable ADAMTS-13 antibodies. ${ }^{55}$ On further investigation, truncated versions of the metalloprotease were found to be present in the patient's plasma indicating the likely proteolytic degradation of ADAMTS-13. The two fragments of ADAMTS-13 in this patient were found to be identical to those observed when plasmin was allowed to digest ADAMTS-13 in a parallel experiment. Although only a single case report, it suggests that acquired deficiencies of the metalloprotease may not always be immune-mediated.

\section{Conclusion}

The examples described above suggest that TMA may precipitate when there is disruption of normal ADAMTS-13 function. This disruption appears to primarily involve the ability of the metalloprotease to bind its supposed endothelial receptor, $\mathrm{CD} 36$. The importance of this binding may be crucial to its role in vivo and it is preposed that the blocking of this binding by antibodies may induce TMA much like that seen in TTP. The recent discovery of these CD36 antibodies in patients with HUS may have finally provided a molecular basis to the clinical and pathological similarities observed in HUS and TTP. As more is learnt in relation to the interactions between ADAMTS-13 and VWF, its localization on the endothelium, and its physiological control by other coagulation proteins, the true significance of ADAMTS-13 in other TMA may be better understood.

\section{References}

1 Lichtman LA, Beutler E, Kipps TJ, Seligsohn U, Kaushansky K, Prchal JT. Williams Hematology. 7th ed. Sydney: McGraw-Hill Medical; 2006

2 Tsai HM. The molecular biology of thrombotic microangiopathy. Kidney Int 2006;70(1):16-23

3 Lämmle B, Kremer Hovinga JA, Alberio L. Thrombotic thrombocytopenic purpura. J Thromb Haemost 2005;3(8):1663-1675 
4 George JN. Diagnosis of thrombotic thrombocytopaenia purpura haemolytic uraemic syndrome in adults. 2010, Available at: www. uptodate.com/contents/diagnosis-of-thrombotic-thrombo-cytopenic-purpura-hemolytic-uremic-syndromeinadults? source=search_result\&search=thombotic+thombocytopaenia+purpura\&selectedTitle=1\%7E150. Accessed October 12, 2010

5 George JN. The role of ADAMTS13 in the pathogenesis of thrombotic thrombocytopenic purpura-hemolytic uremic syndrome. Clin Adv Hematol Oncol 2005;3(8):627-632

6 Desch K, Motto D. Is there a shared pathophysiology for thrombotic thrombocytopenic purpura and hemolytic-uremic syndrome? J Am Soc Nephrol 2007;18(9):2457-2460

7 Tsai HM. Physiologic cleavage of von Willebrand factor by a plasma protease is dependent on its conformation and requires calcium ion. Blood 1996;87(10):4235-4244

8 Furlan M, Robles R, Lämmle B. Partial purification and characterization of a protease from human plasma cleaving von Willebrand factor to fragments produced by in vivo proteolysis. Blood 1996;87 (10):4223-4234

9 Franchini M, Montagnana M, Targher G, Lippi G. Reduced von Willebrand factor-cleaving protease levels in secondary thrombotic microangiopathies and other diseases. Semin Thromb Hemost 2007;33(8):787-797

10 Zhou Z, Nguyen TC, Guchhait P, Dong JF. Von Willebrand factor, ADAMTS-13, and thrombotic thrombocytopenic purpura. Semin Thromb Hemost 2010;36(1):71-81

11 Favaloro EJ. Hemolytic uremic syndrome. Preface. Semin Thromb Hemost 2010;36(6):573-574

12 Karpman D, Sartz L, Johnson S. Pathophysiology of typical hemolytic uremic syndrome. Semin Thromb Hemost 2010;36 (6):575-585

13 Just S. Methodologies and clinical utility of ADAMTS-13 activity testing. Semin Thromb Hemost 2010;36(1):82-90

14 Moschcowitz E. Hyaline thrombosis of the terminal arterioles and capillaries: a hithero undescribed disease. Proc N Y Pathol Soc. 1924;24;21-24

15 Baehr G, Kelmerer P, Schifrin A. Acute febrile anemia and thrombocytopenic purpura with diffuse platelet thrombosis of capillaries and arterioles. Tr A Am Physicians 1936;51:43

16 Singer K, Bornstein FP, Wile SA. Thrombotic thrombocytopenic purpura; hemorrhagic diathesis with generalized platelet thromboses. Blood 1947;2(6):542-554

17 Amorosi EL, Ultmann JE. Thrombotic thrombocytopenic purpura: report of 16 cases and review of the literature. Medicine 1966; $45 ; 139-160$

18 Moake JL, Rudy CK, Troll JH, et al. Unusually large plasma factor VIII:von Willebrand factor multimers in chronic relapsing thrombotic thrombocytopenic purpura. N Engl J Med 1982;307(23): 1432-1435

19 Moake JL, Turner NA, Stathopoulos NA, Nolasco LH, Hellums JD. Involvement of large plasma von Willebrand factor (vWF) multimers and unusually large vWF forms derived from endothelial cells in shear stress-induced platelet aggregation. J Clin Invest 1986;78(6):1456-1461

20 Moake JL, Turner NA, Stathopoulos NA, Nolasco LH, Hellums JD. Shear-induced platelet aggregation can be mediated by vWF released from platelets, as well as by exogenous large or unusually large vWF multimers, requires adenosine diphosphate, and is resistant to aspirin. Blood 1988;71(5):1366-1374

21 Fujikawa K, Suzuki H, McMullen B, Chung D. Purification of human von Willebrand factor-cleaving protease and its identification as a new member of the metalloproteinase family. Blood 2001;98 (6):1662-1666

22 Levy GG, Nichols WC, Lian EC, et al. Mutations in a member of the ADAMTS gene family cause thrombotic thrombocytopenic purpura. Nature 2001;413(6855):488-494

23 Zheng X, Chung D, Takayama TK, Majerus EM, Sadler JE, Fujikawa K. Structure of von Willebrand factor-cleaving protease
(ADAMTS13), a metalloprotease involved in thrombotic thrombocytopenic purpura. J Biol Chem 2001;276(44):41059-41063

24 Kokame K, Matsumoto M, Soejima K, et al. Mutations and common polymorphisms in ADAMTS13 gene responsible for von Willebrand factor-cleaving protease activity. Proc Natl Acad Sci U S A 2002;99(18):11902-11907

25 Lotta LA, Garagiola I, Palla R, Cairo A, Peyvandi F. ADAMTS13 mutations and polymorphisms in congenital thrombotic thrombocytopenic purpura. Hum Mutat 2010;31(1):11-19

26 Tsai HM, Lian EC. Antibodies to von Willebrand factor-cleaving protease in acute thrombotic thrombocytopenic purpura. N Engl J Med 1998;339(22):1585-1594

27 Sheiflinger F, Knobl P, Trattner B, et al. Non-neutralising IgM and IgG antibodies to von Willebrand factor-cleaving protease (ADAMTS-13) in a patient with thrombotic thrombocytopenic purpura. Blood 2003;102(9):3241-3243

28 Key N, Makris M, O'shaunessy D, Lillicrap D. . Practical Hemostasis and Thrombosis. 2nd ed. Singapore: Wiley-Blackwell; 2009

29 De Meyer SF, Deckmyn H, Vanhoorelbeke K. von Willebrand factor to the rescue. Blood 2009;113(21):5049-5057

30 Sadler JE. Biochemistry and genetics of von Willebrand factor. Annu Rev Biochem 1998;67;395-424

31 McGrath RT, McRae E, Smith OP, O’Donnell JS. Platelet von Willebrand factor-structure, function and biological importance. $\mathrm{Br} \mathrm{J}$ Haematol 2010;148(6):834-843

32 Sporn LA, Marder VJ, Wagner DD. von Willebrand factor released from Weibel-Palade bodies binds more avidly to extracellular matrix than that secreted constitutively. Blood 1987;69 (5):1531-1534

33 Arya M, Anvari B, Romo GM, et al. Ultralarge multimers of von Willebrand factor form spontaneous high-strength bonds with the platelet glycoprotein Ib-IX complex: studies using optical tweezers. Blood 2002;99(11):3971-3977

34 Tsai HM. Mechanisms of microvascular thrombosis in thrombotic thrombocytopenic purpura. Kidney Int Suppl 2009;112(112): S11-S14

35 Uchida T, Wada H, Mizutani M, et al; Research Project on Genetics of Thrombosis. Identification of novel mutations in ADAMTS13 in an adult patient with congenital thrombotic thrombocytopenic purpura. Blood 2004;104(7):2081-2083

36 Pimanda JE, Maekawa A, Wind T, Paxton J, Chesterman CN, Hogg PJ. Congenital thrombotic thrombocytopenic purpura in association with a mutation in the second CUB domain of ADAMTS13. Blood 2004;103(2):627-629

37 Zhou Z, Nguyen TC, Guchhait P, Dong JF. Von Willebrand factor, ADAMTS-13, and thrombotic thrombocytopenic purpura. Semin Thromb Hemost 2010;36(1):71-81

38 Zanardelli S, Crawley JTB, Chion CK, Lam JK, Preston RJS, Lane DA. ADAMTS13 substrate recognition of von Willebrand factor A2 domain. J Biol Chem 2006;281(3):1555-1563

39 Vomund AN, Majerus EM. ADAMTS13 bound to endothelial cells exhibits enhanced cleavage of von Willebrand factor. J Biol Chem 2009;284(45):30925-30932

40 Reiter RA, Knöbl P, Varadi K, Turecek PL. Changes in von Willebrand factor-cleaving protease (ADAMTS13) activity after infusion of desmopressin. Blood 2003;101(3):946-948

41 Lippi G, Franchini M, Targher G, Poli G, Guidi GC. The significance of evaluating conventional inflammatory markers in Von Willebrand factor measurement. Clin Chim Acta 2007;381(2): 167-170

42 Mannucci PM, Canciani MT, Forza I, Lussana F, Lattuada A, Rossi E. Changes in health and disease of the metalloprotease that cleaves von Willebrand factor. Blood 2001;98(9):27302735

43 Furlan M, Robles R, Morselli B, Sandoz P, Lämmle B. Recovery and half-life of von Willebrand factor-cleaving protease after plasma therapy in patients with thrombotic thrombocytopenic purpura. Thromb Haemost 1999;81(1):8-13 
54 TMA, TTP, and ADAMTS-13 Chapman et al.

44 Barbot J, Costa E, Guerra M, et al. Ten years of prophylactic treatment with fresh-frozen plasma in a child with chronic relapsing thrombotic thrombocytopenic purpura as a result of a congenital deficiency of von Willebrand factor-cleaving protease. Br J Haematol 2001;113(3):649-651

45 Tandon NN, Rock G, Jamieson GA. Anti-CD36 antibodies in thrombotic thrombocytopenic purpura. BrJ Haematol 1994;88(4):816-825

46 Schultz DR, Arnold PI, Jy W, et al. Anti-CD36 autoantibodies in thrombotic thrombocytopenic purpura and other thrombotic disorders: identification of an $85 \mathrm{kD}$ form of CD36 as a target antigen. Br J Haematol 1998;103(3):849-857

47 Rock G, Chauhan K, Jamieson GA, Tandon NN. Anti-CD36 antibodies in patients with lupus anticoagulant and thrombotic complications. Br J Haematol 1994;88(4):878-880

48 Rock GA, Clark WF. Mechanism of microthrombosis in HUS. Kidney Int Suppl 2009;75(112):S15-S16

49 Nolasco LH, Turner NA, Bernardo A, et al. Hemolytic uremic syndrome-associated Shiga toxins promote endothelial-cell secretion and impair ADAMTS13 cleavage of unusually large von Willebrand factor multimers. Blood 2005;106(13):4199-4209
50 Morishita K, Wakamoto S, Miyazaki T, et al. Life-threatening adverse reaction followed by thrombocytopenia after passive transfusion of fresh frozen plasma containing anti-CD36 (Nak $\left.{ }^{\mathrm{a}}\right)$ isoantibody. Transfusion 2005;45;803-806

51 Wakamoto S, Fujihara M, Urushibara N, et al. Heterogeneity of platelet responsiveness to anti-CD36 in plasma associated with adverse transfusion reactions. Vox Sang 2005;88(1): 41-51

52 Tomiyama Y, Kunicki TJ, Zipf TF, Ford SB, Aster RH. Response of human platelets to activating monoclonal antibodies: importance of Fc gamma RII (CD32) phenotype and level of expression. Blood 1992;80(9):2261-2268

53 George JN. ADAMTS13: what it does, how it works, and why it's important. Transfusion 2009;49(2):196-198

54 Crawley JT, Lam JK, Rance JB, Mollica LR, O’Donnell JS, Lane DA. Proteolytic inactivation of ADAMTS13 by thrombin and plasmin. Blood 2005;105(3):1085-1093

55 Feys HB, Vandeputte N, Palla R, et al. Inactivation of ADAMTS13 by plasmin as a potential cause of thrombotic thrombocytopenic purpura. J Thromb Haemost 2010;8(9):2053-2062 